\title{
Using Facebook for travel decision- making: an international study of antecedents
}

Article

Accepted Version

Text

Mariani, M., Ek Styven, M. and Ayeh, J. K. (2019) Using Facebook for travel decision-making: an international study of antecedents. International Journal of Contemporary Hospitality Management, 31 (2). pp. 1021-1044. ISSN 0959-6119 doi: https://doi.org/10.1108/IJCHM-02-2018-0158 Available at https://centaur.reading.ac.uk/79982/

It is advisable to refer to the publisher's version if you intend to cite from the work. See Guidance on citing.

To link to this article DOI: http://dx.doi.org/10.1108/IJCHM-02-2018-0158

Publisher: Emerald

All outputs in CentAUR are protected by Intellectual Property Rights law, including copyright law. Copyright and IPR is retained by the creators or other copyright holders. Terms and conditions for use of this material are defined in the End User Agreement.

www.reading.ac.uk/centaur 
Central Archive at the University of Reading

Reading's research outputs online 


\title{
Using Facebook for travel decision-making: An international study of antecedents
}

\begin{abstract}
Purpose: This study investigates antecedents of using non-travel-specific social media (specifically Facebook) for travel decision-making before a leisure trip.

Design/methodology/approach: Based on an online survey of 426 young travel consumers from Italy and Sweden, this work applies structural equation modeling and multi-group analysis.

Findings: The study finds support for most of the conventional TAM-related constructs: perceived usefulness, perceived enjoyment, and intention, while ease of use is not found relevant in this context.
\end{abstract}

Research limitations/implications: Results shed light on the antecedents of using non-travelspecific social media in two countries. Future research might focus on validating the factors identified and add others that might shape usage in the selected countries. Future studies could further investigate possible differences arising from culture, country of origin and age. The analysis can also be extended to other countries.

Practical implications: The analysis might help managers in the hospitality and tourism sector by providing an understanding of the cognitive factors which determine travelers' decision to use Facebook for trip planning. Thus, managers should get to know these factors in their effort to influence social media in hospitality and tourism settings.

Originality/value: The findings offer interesting perspectives on the applicability of conventional models to the context of non-travel-specific social media platforms. The exploration of crosscultural differences also adds to the extant body of knowledge.

Keywords: Social media; Facebook; Young travelers; Technology Acceptance Model; Enjoyment 
Article Classification: Research paper 


\section{Introduction}

Social media (SM) have radically changed the way people interact with companies and brands, share their ideas and opinions and review products and services. This is particularly true in hospitality and tourism where SM have been increasingly adopted by companies and destinations to effectively engage with their potential guests and visitors. SM allow Internet users to shape virtual travel communities, enabling tourists to obtain and share information, cultivate connections, share their opinions and reviews, develop relationships (Wang et al., 2002) and potentially make travel-related decisions (Ayeh et al., 2013b).

Undoubtedly, one of the most important SM platforms in the $21^{\text {st }}$ century is Facebook. Currently, it is the most popular social medium worldwide, with over 2.23 billion monthly active users as of June 30, 2018 (Facebook, 2018). While Facebook is recognized as a general social network site (Kuchler, 2016), its growing importance in the domain of travel and tourism cannot be overemphasized. Many scholars have underscored the utility of Facebook for sharing travel-related media (travel photos, videos, experiences, etc.) during and after travel (e.g., Kim and Fesenmaier, 2017). More recently, some researchers have observed its increasing role in supporting travel planning or decision making at the pre-trip stage (Jadhav et al., 2018; Lee et al., 2012). Scholars recognize the role of Facebook in hospitality and tourism marketing (e.g., Ben-Shaul and Reichel, 2018; Lo and Fang, 2018; Mariani et al., 2016; Su et al., 2015) and in tourism-related decision making (e.g., Lee et al., 2012). Recent initiatives by Facebook - such as embedding in the instant messaging platform a new service allowing for booking flights and accommodation (Kuchler, 2016) and developing trip planning products such as "Trip consideration" - further accentuates the growing significance of this platform for travel planning. Moreover, travel specific platforms such as Skyscanner and online travel agencies (OTAs) such as Expedia are increasingly accessed via 
Facebook and Facebook Messenger, and their apps are frequently downloaded through Facebook. Many travel companies are increasingly investing in non-travel-specific social media to allow their customers to purchase via those social networks: for instance, KLM's (Royal Dutch Airline) Facebook followers can book, change or cancel a flight by sending over details through social media platforms.

Clearly, non-travel-specific social media are paying increasing attention to emerging trends in their users' behaviors in terms of travel-related decisions (i.e., decisions related to tourism destinations, accommodation, and transportation). Hospitality and tourism companies are significantly investing in Facebook advertising to increase their appeal to consumers and potential buyers (Su et al., 2015). What seems to have escaped research attention, however, are the possible cognitive and affective mechanisms driving travelers' usage for the particular purpose of trip planning, given the general nature of these platforms. In other words, there is a lack of empirical evidence and understanding of the factors influencing the use of general non-travel-specific SM (Facebook, Twitter, etc.) for travel decision making before a leisure trip. A few scholars have explored the determinants of consumer-generated media (CGM) usage for travel planning. However, these studies predominantly focused on travel-specific platforms like TripAdvisor, C-Trip and other travel review sites (e.g., Ayeh et al., 2013b, 2016; Filieri, 2016). Yet, as a general social network site, Facebook is very distinct from travel-specific CGM platforms like TripAdvisor and third-party commercial websites like Booking.com, Expedia.com, and Hotels.com. Besides, extant literature on the technology stream of research demonstrates that determinants of use often differ in concomitant to the context, task and type of technology being studied (Lee et al., 2012; Moon and Kim, 2001). This implies that the cognitive and affective mechanisms determining usage of general social media platforms like Facebook for holiday planning may be very different from what we 
already know about travel-specific platforms like TripAdvisor and third-party commercial websites and OTAs like Booking.com and Expedia.com. To address this gap, this study investigates the antecedents of using non-travel-specific social media (namely Facebook) for travel decision making. We situate our analysis in an international context encompassing two countries: Italy and Sweden.

The paper is structured as follows. Next section reviews previous research and illustrates the research model with an emphasis on the proposed hypotheses. After that, the methodology is described. The ensuing section reports and discusses the research findings. The last section draws the conclusions, elucidates the managerial implications of the study, and identifies limitations as well as avenues for future research.

\section{Literature and hypothesis development}

Social media are playing a crucial role within the travel and tourism industry as witnessed by the plethora of industry reports that have been constantly issued over the last five years (see for instance comScore, 2018a, 2018b; Google, 2014; PhocusWright, 2014). The increasing importance of SM in travel has triggered a deep interest by the wide community of eTourism researchers who have identified 'Travel 2.0' as one of the most noticeable "mega trends" affecting the tourism system (Leung et al., 2013). Recent research has investigated the relevance of SM for hotels (Kim et al., 2015b; Kim and Park, 2017; Mauri and Minazzi, 2013; tom Dieck et al., 2017), restaurants (Kim et al., 2015a), attractions (Dickinger et al., 2017) and destinations (Hays et al., 2012; Mariani et al., 2016, 2018) to effectively engage with their potential customers and guests. SM generate benefits related to not only the possibility of collecting information and reviews from peers before a trip (e.g., Litvin et al., 2008), but also to sharing information during and after a trip and 
maintaining relationships within a SM community (Perez-Vega et al., 2018; Qu and Lee, 2011).

Despite the increasing body of research on SM within the eTourism literature (e.g., Xiang and Gretzel, 2010), the drivers of SM use for the objective of travel planning have been rarely tackled. In this study, we leverage the Technology Acceptance Model (Davis, 1986), along with motivation theory to understand the antecedents of travelers' intention to use non travel specific SM for travel decision making. Since social media do not only symbolize technology (Web 2.0) but also content (information), and given the study's focus on its use as an information source for travel decision making, we employ elements of the credibility theory to address the information adoption perspective. While utilizing several components of the model by Ayeh et al. (2013b) to develop a more joined-up body of knowledge for studies adopting structural equation modeling approaches, our study is innovative as it is to our knowledge the first to investigate the factors affecting SM users' intentions to use a non-travel-specific social medium for travel-related decisions before a leisure trip. Using an American sample, Ayeh et al.'s (2013b) study examined travelers' conative response to using CGM from travel-specific platforms (i.e., TripAdvisor). In contrast, our study employs two European samples (Italian and Swedish) to investigate the intention to use a general (non-travel-specific) SM platform (Facebook) for travel decision-making. Thus, this study further provides an international perspective in the area of online travel-related behavior, which so far has been largely studied in countries such as the US and China (Amaro and Duarte, 2013).

\section{The Technology Acceptance Model (TAM)}

The Technology Acceptance Model (TAM), which is more parsimonious and easily adaptable to different settings than its later extensions, is considered as the most established theory to explain individuals' acceptance and use of information systems (Bagozzi, 2007). The model assumes that 
an individual's perception of the ease of use and usefulness of a technological system determines his/her attitude and behavioral intention toward the use of that system. Ease of use is also considered to positively influence usefulness (Davis, 1986). Furthermore, “Attitude toward using", defined as "the degree of evaluative affect that an individual associates with using the target system" (Davis, 1986, p. 25), is expected to have a directly positive relation to behavioral intention.

The TAM was originally developed to explain use of information systems in organizational settings (Davis, 1986), but has been applied in a number of different contexts to analyze the adoption of new technologies and to explain and forecast technology users' behaviors (Ayeh, 2015; Morosan, 2012). One of the major shortcomings of research founded on the TAM is that findings are tightly linked to the specific task under analysis (Moon and Kim, 2001). Hence, by extending previous research, TAM is applied in this study to investigate the use of non-travel-specific SM for travel decision making.

In the context of this study, perceived usefulness describes travelers' expectations that using nontravel-specific SM will enhance their travel planning. This antecedent has been identified as a basic driver of technology deployment in travel and tourism settings (Ayeh et al., 2013b; Huh et al., 2009; Morosan, 2012). As usefulness relates to specific objectives or tasks, the system might lose its usefulness when it is taken out of the original context (Lee et al., 2012; Xiao and Smith, 2007). Our focus here is on prospective travelers looking for travel information, and in this context the usefulness of non-travel-specific SM is related to the extent to which the particular social medium helps consumers in their travel planning and decision making. As a consequence, we hypothesize perceived usefulness to influence travelers' attitude and intention to use non-travel-specific SM for travel planning. The usefulness-attitude relationship is supported by a number of studies in other 
contexts (Agag and El-Masry, 2016; Huh et al., 2009; Pavlou and Fygenson, 2006). Moreover, several studies have measured a direct relationship between usefulness and intention (e.g., Ayeh, 2015; Ayeh et al., 2013b; Besbes et al., 2016; Huh et al., 2009). In view of this, the following hypotheses are proposed:

Hla: Perceived usefulness of content from a non-travel-specific SM platform positively influences attitude towards its use for trip planning.

$H 1 b$ : Perceived usefulness of content from a non-travel-specific SM platform positively influences the behavioral intention to use it for trip planning.

The influence of ease of use in the context of the TAM has been validated in previous research in travel and tourism (e.g., Ayeh et al., 2013b; Casaló et al., 2010; Huh et al., 2009; Morosan, 2012). The theory postulates that a system will be considered as more useful if it is easy to use. Many previous studies provide strong support for this relationship between ease of use and usefulness (e.g., Ayeh, 2015; Ayeh et al., 2013b; Morosan, 2012). At the same time, Venkatesh and Davis (2000) note that, compared to perceived usefulness, ease of use has exhibited a less consistent effect on behavioral intention across studies. For instance, Kim (2016) found a non-significant relation between ease of use and intention to use hotel tablet apps. In the context of this study, perceived ease of use is related to the extent to which a person believes that using the SM platform will not be burdensome and will require minimal efforts. Social media are generally believed to enhance convenience in information search and travel planning. We therefore hypothesize that individual travelers' evaluation of the amount of effort required when using the SM platform will influence their attitudes as well as their perception of usefulness.

$H 2 a$ : Perceived ease of using a non-travel-specific SM platform positively influences attitude towards its use for trip planning. 
$H 2 b$ : Perceived ease of using a non-travel-specific SM platform positively influences its perceived usefulness for trip planning.

$H 2 c$ : Perceived ease of using a non-travel-specific SM platform positively influences the behavioral intention to use it for trip planning.

In this study's case, the attitude construct is presumed to be related to using non-travel-specific SM for travel planning. The relationship between attitude toward a given object or behavior and behavioral intention has been significantly explored in consumer behavior models (e.g., Ajzen, 1991; Shim et al., 2001) and hereafter has been well documented in the mainstream literature of information systems and general marketing (Pavlou and Fygenson, 2006; Venkatesh et al., 2003) as well as that of travel and tourism (Ayeh et al., 2016; Huh et al., 2009; Lee et al., 2012; Morosan, 2012). Therefore, we hypothesize:

H3a: Attitude towards using a non-travel-specific SM platform positively influences the behavioral intention to use it for trip planning.

\section{Motivation theory}

Motivation theory is another theoretical lens that is often deployed in psychology and marketing studies (Brown et al., 2015; Ryan and Deci, 2001; Venkatesh, 2000). It has been applied in the form of a motivational model by Davis et al. (1992) postulating that Internet users' behaviors differ depending on whether their motivation is intrinsic or extrinsic. Intrinsically motivated behavior refers to doing an activity for its own sake (e.g., because it is interesting, engaging, or satisfying), whereas extrinsic motivation concerns the drive to carry out a certain behavior because of dictates of others, or with the purpose of realizing reward or recognition (Lee et al., 2005). Perceived usefulness is an example of extrinsic motivation. Hence, while extrinsic motivation comes from a 
fairly rational calculation of benefits (Lee et al., 2005), the nature of intrinsic motivation is more hedonic.

To capture the intrinsic motivation in relation to IT use, the construct of perceived enjoyment has been added to the original TAM as one of the predicting variables for different types of behavioral intentions (Kang and Schuett, 2013; Lee et al., 2005). In some research contexts, the construct has been found to be a weaker predictor of behavioral intentions than perceived usefulness and ease of use (e.g., Mathieson et al., 2001), but it seems that perceived enjoyment may have a stronger effect when it comes to usage of more hedonic systems (van der Heijden, 2004) such as social media (Amaro et al., 2016). In the travel and tourism context, prospective travelers in search for information might be more interested in browsing other travelers' social media content such as photographs, videos, and comments (intrinsic motivation), rather than in the outcome of the information search process per se (extrinsic motivation) (Castañeda et al., 2007).

Previous research has found that perceived enjoyment affects travelers' perceived ease of use, attitudes and behavioral intention to use CGM for travel planning (Ayeh et al., 2013b). Recently, a significant link between enjoyment and perceived usefulness of CGM has also been added (Ayeh et al., 2016). These studies analyzed consumers' perceptions and intentions in relation to a travelrelated website; i.e., TripAdvisor. In our empirical setting (i.e., Facebook), the impact of the aforementioned construct might be even more relevant, considering that perceived enjoyment may have a stronger effect when it comes to usage of more hedonic systems such as social media (Amaro et al., 2016; van der Heijden, 2004). Consequently, we put forward the following hypotheses:

H4a: Perceived enjoyment positively influences perceived ease of using a non-travelspecific SM platform for trip planning. 
$H 4 b$ : Perceived enjoyment positively influences attitude towards using content from a nontravel-specific SM platform for trip planning.

H4c: Perceived enjoyment positively influences the behavioral intention to use content from a non-travel-specific SM platform for trip planning.

H4d: Perceived enjoyment positively influences perceived usefulness of content from a non-travel-specific SM platform for trip planning.

\section{Credibility theory and trustworthiness}

In communication and information science, the credibility theory poses that credibility is a multifaceted and complex concept (Wathen and Burkell, 2002) resulting from the interaction of source characteristics (e.g., trustworthiness, expertise), message characteristics, the media, and receiver characteristics. Nonetheless, the most widely used source-related components are trustworthiness and expertise (Wathen and Burkell, 2002). Yet researchers recognize that judging expertise in online contexts is problematic, particularly in the current Web 2.0 environment where anyone could post content online (Burgess et al., 2011; Park et al., 2014). Accordingly, previous research has often found the influence of source expertise to be weak, insignificant or irrelevant in CGM contexts (e.g., Ayeh, 2015; Ayeh et al., 2013a). Hence, we omit the expertise dimension in our model. In online settings, trustworthiness is regarded as a key aspect leading to acceptance (Dickinger, 2011). Source trustworthiness is viewed as the consumer's perception that a source of communication is dependable, sincere, honest, and reliable (Ohanian, 1990).

According to Dickinger (2011), user-generated content in the form of TripAdvisor reviews is perceived as highly trustworthy, while editorial content providers (e.g., tourist boards) are regarded as more informative. Similarly, Ip et al. (2012) note that consumers tend to trust information from 
CGM more than information from service providers. This may sound counter-intuitive, considering the difficulty to assess the quality of this information. Research in eWOM has investigated the role of source trustworthiness in consumer decisions and received mixed results (Filieri, 2016). While a few studies found that source trustworthiness may not directly influence intentions to use information online in certain contexts (Ayeh et al., 2016; Cheung et al., 2008), others have concluded that source trustworthiness affects intentions to book travel online (Besbes et al., 2016), as well as utilitarian and social functions (benefits) of online communities (Reichelt et al., 2014).

While a thorough understanding of how consumers assess source trustworthiness in online environments is yet to be reached (Filieri, 2016), it appears that consumers tend to regard information from their peers (in this case, SM users) as trustworthy (Litvin et al., 2008; Mauri and Minazzi, 2013). Moreover, a significant amount of empirical evidence suggest that perceived trustworthiness has the potential to influence intention and attitude (Besbes et al., 2016). Consequently, we expect that prospective travelers' perception of the trustworthiness of non-travelspecific SM sources will have a positive effect on their attitudes toward the use of social media for travel planning as well as their perception of the usefulness of the content.

H5a: Perceived trustworthiness positively influences perceived usefulness of content from a non-travel-specific SM platform for trip planning.

$H 5 b$ : Perceived trustworthiness positively influences attitude towards using content from a non-travel-specific SM platform for trip planning.

H5c: Perceived trustworthiness positively influences the behavioral intention to use content from a non-travel-specific SM platform for trip planning. 


\section{Hypothesized model}

Overall, travelers' perceptions of usefulness, ease of use, enjoyment, and trustworthiness are hypothesized to affect their attitude and behavioral intention to use non-travel-specific SM for travel planning (Fig. 1). Behavioral intention is understood as a person's subjective probability that he or she will exhibit a given behavior (Ajzen, 1991). This construct represents the individual traveler's subjective probability to use content from non-travel-specific SM platform for trip planning.

\section{[INSERT FIGURE 1 ABOUT HERE]}

\section{Research methodology}

\subsection{Instrument design}

This work adopts a quantitative approach in line with previous research on usage intention (e.g., Ayeh et al., 2016; Venkatesh et al., 2003). A survey instrument was developed on the basis of established measures of constructs from tourism, marketing, and information systems literature. More specifically, the TAM-related measures; i.e., perceived usefulness (five items), perceived ease of use (five items), attitude (five items), and intention to use (four items), as well as enjoyment (five items), were adapted from studies conducted by Ayeh et al. (2013b), which drew the measures from earlier studies on TAM (Davis, 1989; Davis et al., 1989; Davis et al., 1992; Venkatesh et al., 2003) and established their validity and reliability. Trustworthiness was measured with four items adapted from Ohanian (1990). Seven-point semantic differential scales were used in measuring the attitude and trustworthiness constructs. The items of the remaining constructs were measured with seven-point Likert-type scales, with anchors ranging from "not likely at all" (1) to "very likely" (7) for intention to use, and from "strongly disagree" (1) to "strongly agree" (7) for the other three constructs. For descriptive purposes, we also included the variables travel experience (three items, 
adapted from Teichmann, 2011), Facebook use frequency (adapted from Findahl and Davidsson, 2015), and number of Facebook friends (Dunbar, 2016).

An item screening test was carried out with an expert panel of seven scholars, who rated the appropriateness of the items in each scale and suggested alternatives where applicable. The questionnaire was then translated by the researchers to Italian and Swedish, and these versions were checked by colleagues who are also native speakers in the respective language.

\subsection{Data collection and sampling}

The population of this study consists of people belonging to the Millennial generation; i.e. those born from the late 1970s to the early 2000s, who have grown up in an increasingly digitally connected world. Recent statistics show that the age groups between 18 and 34 constitute more than half (57\%) of Facebook users worldwide (Statista, 2018). An online survey, built on the web platform Qualtrics, was deployed to collect data. Online surveys have been employed successfully in the recent hospitality and tourism literature (Hung and Law, 2011), and have the benefit of minimizing social desirability bias. A screening question was asked at the beginning of the questionnaire: "Do you have an active Facebook account?" The survey was introduced by clarifying the purpose of the study and participants were instructed to think about "Facebook content" as content related to leisure travels posted by their Facebook friends or at tourism companies or destinations' official Facebook pages. Sponsored and promoted posts as well as advertising were excluded. Participants could not access the online questionnaire until they had read the introduction carefully.

In order to reach people representing the target population, a purposive sampling approach was 
used. Respondents were partially selected from a research company's online database and partially from mailing lists of university students in Italy and Sweden. These two countries were chosen because: 1) they display different though high levels of Facebook penetration: 50.2 and 62.5 percent respectively in Italy and Sweden (internetworldstats.com, 2017); 2) they differ in terms of cultural dimensions, especially in relation to masculinity, uncertainty avoidance and indulgence (Hofstede-Insights, 2018; Hofstede et al., 2010); 3) Italy is the $8^{\text {th }}$ largest outbound market in the world, while Sweden displays smaller absolute numbers in terms of outbound travelers. The questionnaire was also shared virally on Facebook, in line with the recommendation of Zeng and Gerritsen (2014). In total, 467 people responded to the survey but 41 were screened out as they were non-users of Facebook; resulting in a final sample size of 426.

\subsection{Data analysis}

To estimate our theoretical model and test our hypotheses we applied structural equation modeling (SEM) with maximum likelihood estimation, by using the software SPSS Amos 23. Similar to the majority of studies employing structural equation models, we do not aim to capture strictly causal relationships; rather, the aim is to observe functional relationships and plausible influences among constructs (cf. Bagozzi and Yi, 2012). Though structural equation modeling generally requires larger samples than multiple regression, models can perform well even with samples as small as 100, provided that there are five or fewer constructs, data are normally distributed, item communalities are high, measures are reliable, and there are at least three items per construct (Hair et al., 2010; Iacobucci, 2010). Our model has six constructs and meets the other criteria put forward by Hair et al. (2010). Thus, the sample size of 426 is considered more than adequate to perform the desired analyses. 


\subsection{Measurement validation}

First, we checked all variables for normality and missing data. The assessment of normality showed that the distribution was fairly normal for all variables. Kurtosis values were well within recommended levels (Hair et al., 2007); however, three of the five perceived ease of use items (PEOU 1, 3, and 5) were negatively skewed at levels slightly below -1 . The ratio between mean and standard deviation was above 4 for two of these variables, suggesting that a transformation would not result in a noticeable effect (Hair et al., 2010). Considering this, together with the fairly large sample size which decreases the impact of non-normality on results (Hair et al., 2010), and the controversy surrounding transformation of data (Pallant, 2013), we decided to keep these variables in the analysis without transformation. There were few missing values, but since SEM estimation requires complete data to obtain certain output (e.g., modification indices), we used the Expectation-Maximization method to replace all missing values in the quantitative variables. According to Hair et al. (2010), this approach introduces the least amount of bias into structural equation models.

As part of the validation, we ran linear regressions in order to check multicollinearity between the constructs by examining the variance inflation factor (VIF) and tolerance values of all variables in the model. A VIF exceeding 10 and a corresponding tolerance of less than .10 would indicate that the variable to a large extent is predicted by other independent variables and the degree of multicollinearity is too high (Hair et al., 2010). No variables were close to these thresholds; the highest VIF was 2.26.

Next, we ran a confirmatory factor analysis in Amos to evaluate and refine the scales (Gerbing and Anderson, 1988). Based on assessments of model fit indices, factor loadings, standardized 
residuals, and modification indices, three items were dropped (ENJ5, PEOU2, and PEOU4). In all three instances, dropping the item resulted in an increase, or only slight decrease, of Cronbach's alpha. The final measurement model had a $\chi^{2} / \mathrm{df}$ of $2.088(p<.001), \mathrm{CFI}=.971$, and RMSEA $=.051$ at $p=.426$, suggesting good fit between the model and data. Discriminant and convergent validity among constructs was assessed by examining whether (1) all standardized factor loadings were significant and higher than .50; (2) the squared correlations between each pair of constructs were less than the square root of the average variance extracted (AVE) for each construct; and (3) the average variance extracted for each construct was higher than .50 (Fornell and Larcker, 1981; Hair et al., 2010). These criteria were met with the exception of perceived usefulness - intention to use, which were very strongly correlated (see Table 1). Testing the model with all usefulness and intention items as indicators of the same construct resulted in worse fit $\left(\chi^{2} / \mathrm{df}=2.511, \mathrm{CFI}=.960\right.$, and RMSEA $=.060$ at $\mathrm{p}=.003$ ), suggesting that the constructs were closely related but separate (cf. Hair et al., 2010). All items and their factor loadings are included in the Appendix.

Table 1 shows the Cronbach alphas and AVEs of all constructs, together with the squared correlations between constructs:

[INSERT TABLE 1 ABOUT HERE]

\section{Findings}

\subsection{Sample characteristics}

In the total sample, 47 percent were between 16 and 24 years old; the remaining 53 percent were 26-40 years. Women were slightly over-represented, making up 57 percent of the sample. Due to the sampling method, more than half of the respondents $(54.6 \%)$ were students, while 32.2 percent were working. Table 2 summarizes the characteristics of respondents. 


\section{[INSERT TABLE 2 ABOUT HERE]}

Respondents in both countries had very similar levels of Facebook use frequency and self-assessed travel experience, but the two samples differed significantly in terms of gender, age, occupation, and number of Facebook friends. The Italian respondents indicated that they, on average, had 401500 Facebook friends, while the mean (and median) in the Swedish sample corresponded to the category 201-300 friends. We also found that the number of friends correlates negatively with age ( $r=-.202, p<.001)$. When comparing this variable between the age groups 16-24 and 25-40, the mean in the younger group was 4.91 ; i.e. close to the category $301-400$ friends, while the mean in the older group was $4.11(t=4.315, p<0.001)$. These findings suggest that younger users have larger online networks, which corresponds to Dunbar's (2016) results. This could also explain the difference between the two samples with regard to number of Facebook friends, since the Italian sample was overall younger.

To address possible influences of the identified differences between the two samples as well as cross-cultural influences, we ran a number of multigroup analyses of the model, which are described further on in the paper.

\subsection{Structural model and hypothesis testing}

To test the hypotheses, we estimated the path model in Amos with maximum likelihood estimation, using the full sample $(n=426)$. Model fit was satisfactory with $\chi 2 / \mathrm{df}=2.133(p<.001), \mathrm{CFI}=.970$, and RMSEA $=.052$. The relationships for $\mathrm{H} 2 \mathrm{c}, \mathrm{H} 3 \mathrm{a}, \mathrm{H} 4 \mathrm{c}$, and $\mathrm{H} 5 \mathrm{c}$ were non-significant, while all other relationships were significant as hypothesized, with one important exception. Perceived ease of use had a significant but negative relation to perceived usefulness $(\mathrm{H} 2 \mathrm{~b})$; probably because of the skewness of the observed variables in this construct (mean 5.76, standard deviation 1.28, and 
skewness -1.1.). That is, as Millennial consumers take the ease of using SM for granted, the variance is rather low and ease of use is not necessarily related to other constructs in a way that would be expected in older age groups. We therefore decided to remove PEOU from the model and run it again.

Fit measures indicate that the revised model fits the sample data well: $\chi 2 / \mathrm{df}=2.253(p<.001), \mathrm{CFI}$ $=.972$, and RMSEA $=.054$. Even though $\chi 2$ is significant at the $5 \%$ level, this could be attributed to the large sample size (Hair et al., 2010); thus, the level of fit is regarded to be satisfactory overall. Figure 2 below shows the standardized path estimates and squared multiple correlations (corresponding to $R^{2}$ ) of the revised model.

\section{[INSERT FIGURE 2 ABOUT HERE]}

Results show that the model could explain 24.5 percent of the variance in perceived usefulness, 59.0 percent of the variance in attitude, and 83.6 percent of the variance in intention to use Facebook for travel planning. Therefore, the proposed revised model (which excludes ease of use) can be assumed to sufficiently reflect travelers' intention to use content from a non-travel-specific social media platform for trip planning. Essentially, perceived usefulness, enjoyment and trustworthiness drive attitudes in this context while perceived usefulness represents the prime determinant of intention.

Hypotheses 1a and 1b, which assume direct positive relationships between perceived usefulness of content from non-travel-specific SM platforms and travelers' attitude (Beta=.571, t=17.747, $p<0.01)$ and intentions (Beta=0.897, $\mathrm{t}=19.063, p<0.01)$ were verified. Perceived ease of use was dropped from the model for the reasons explained before; thus, H2a-c and H4a were not tested. 
Perceived enjoyment was found to be positively related to attitude $($ Beta $=0.145, \mathrm{t}=4.567, p<0.01)$ and usefulness $(\mathrm{Beta}=0.434, \mathrm{t}=11.505, p<0.01)$ while it displayed no significant relationship with intention. In contrast to social psychology theory on human behavior, attitude has a positive relationship with intention but not statistically significant in the overall sample. Thus, we found only partial support for the traditional TAM model. This supports previous observation by some scholars that TAM applies differently to varying contexts (Ayeh et al., 2013b; Moon and Kim, 2001). Hence, the distinct context of this study and the peculiarity of the EOU variable (as previously highlighted) may explain this finding. Perceived usefulness is the most influential factor for both attitude and intention. Lastly, perceived trustworthiness had a statistically positive relationship with usefulness $(\operatorname{Beta}=0.117, \mathrm{t}=3.259, p<0.01)$ and attitude $($ Beta=0.231, $\mathrm{t}=7.950$, $p<0.01)$ while its relationship with intention was non-significant. Table 3 summarizes the results of the hypothesis tests.

\section{[INSERT TABLE 3 ABOUT HERE]}

To further investigate the relationships that were not supported (i.e., the paths from trustworthiness, enjoyment, and attitude to intention to use), we tested for mediation effects. A precondition for mediation is that the relationship between the independent and the dependent variable is significant in the absence of the mediator, but decreases when the mediator is added (Baron and Kenny, 1986). When excluding perceived usefulness, the relationship between enjoyment and intention became significant at $p<0.05(\mathrm{Beta}=0.140, \mathrm{t}=1.841)$, while the path from trustworthiness to intention remained unchanged. We therefore ran the Sobel test (Sobel, 1982) to check whether attitude in fact worked as a mediator between enjoyment and intention. However, with a test statistic of 0.411 and one-tailed $p=0.340$, this mediation effect could not be verified.

\subsection{Multigroup analysis}


In order to test for possible differences between the Italian and the Swedish sub-sample, we performed a multigroup analysis in Amos. Each estimated path was constrained to be equal in both groups (i.e., with one degree of freedom). A significant difference in Chi-square between the unconstrained and the constrained model indicates that the strength of the path coefficient in fact differs between the two country samples (Hair et al., 2010). Results of the multigroup analysis are displayed in Table 4. Significant differences between groups are marked with bold text.

\section{[INSERT TABLE 4 ABOUT HERE]}

As Table 4 indicates, eight out of the nine estimated relationships did not differ significantly between the two country sub-samples. Still, it could be noted that though the effects on most of the variables were very similar in both groups, the path relationship between enjoyment and attitude was significant in the Swedish sample but not in the Italian sample. Given that Swedish culture scores substantially higher in Indulgence (78) compared to Italian culture (30), it is not surprising that enjoyment seems more influential in the Swedish sample. Conversely, the influence of trustworthiness on perceived usefulness was salient in the Italian group but non-significant in the Swedish group. Comparing the two cultures (Hofstede-Insights, 2018; Hofstede et al., 2010), Italians tend to avoid uncertainties and are thus less willing to take risks, in contrast to their Swedish counterparts. Therefore, source trustworthiness may play a more integral role in their judgement of the utility of travel content from Facebook. Nonetheless, since these observed differences could not be confirmed statistically, the findings warrant further research into these relationships.

Notwithstanding, there was a significant difference in the model between the two countries with regard to the effect of attitude on intention to use. While this relationship was non-significant in the total sample as well as in the Italian sub-sample, the multigroup analysis showed that it was 
positive and significant in the Swedish group, and thus offered support for hypothesis 3 (H3a). The Sobel test confirmed that attitude worked as a mediator between usefulness and intention (test statistic $=1.820$, one-tailed $p<0.05)$, but not for trustworthiness or enjoyment.

To assess whether this difference could be explained by any of the respondent characteristics other than country, we tested the path between attitude and intention, using the variables that differed between the samples. That is, we ran the multigroup analysis comparing respondents based on age, gender, occupation (students vs. non-students), and number of Facebook friends. For the latter variable, we used median split to identify groups with "low" vs. "high" number of Facebook friends, respectively (cf. Kim et al., 2014). Results of the tests are summarized in Table 5 and indicate that none of these variables caused a significant change in Chi-square. That is, we cannot explain the difference in strength and significance of the relationship between attitude and intention with any other variable than country. We might then conjecture that cultural differences (Hofstede et al., 2010) could play a crucial role in the relationship between attitude and intention to use. Though both cultures are generally individualistic, Italy and Sweden differ significantly along three dimensions: masculinity, uncertainty avoidance and indulgence. In the case of uncertainty avoidance, Italy's score is much higher than that of Sweden (75 for Italians vs. 29 for Swedes). This might imply that Italians tend to take less risk than Swedes and thus would rely more on cognitive judgment and less on emotions (attitude) than Swedes when making decisions on highrisk products like travel. Moreover, societies that score high in masculinity (Italy: 70; Sweden: 5) tend to be driven more by competition, achievement and success and are therefore more dependent on cognitive beliefs than on emotions in decision making. 


\section{Discussion and Conclusions}

\subsection{Conclusions}

This work set out to address a gap in extant literature regarding the use of general social media sources for trip planning. More specifically, we analyzed the extent to which prior findings on the antecedents of CGM usage for trip planning "could be generalized to non-travel-specific CGM platforms" (Ayeh et al., 2013b, p. 141) by leveraging a revised version of the TAM encompassing novel factors.

The comparison of our results with previous TAM research related to other settings and to the travel and tourism setting reveals interesting findings. The study found support for most of the conventional TAM-related constructs: perceived usefulness, perceived enjoyment, and intention. Nonetheless, ease of use appeared to be irrelevant in this context. Consistent with extant research (Kim, 2016; Mathieson et al., 2001; Venkatesh, 2000), perceived usefulness is found to be the most influential factor for attitude and behavioral intention. Accordingly, young travelers might use nontravel-specific SM for travel planning if they realize that doing so is useful. Interestingly, enjoyment is a weaker predictor of such a utilitarian goal.

These findings seem to be in contrast with previous studies in certain CGM contexts. For instance, in the case of TripAdvisor, Ayeh et al. (2013b) found that ease of use and enjoyment were most influential as predictors of travel planning intentions. Unlike TripAdvisor, Facebook's primary purpose is social networking and not travel planning. Thus, the perceived usefulness for travel planning represents a more critical criterion for the decision to use it for travel planning. While previous studies found intrinsic motivation for using social media (enjoyment, representing hedonic value) to be more influential than extrinsic motivation (usefulness, representing utilitarian 
value) in determining travelers' intention, our results indicate that extrinsic motivation is what matters most in the context of non-travel-specific SM. Alternatively, the discrepancy might be reconciled with recent cross-country research (Ayeh et al., 2016) emphasizing that cultural differences matter and that perceived usefulness is a more important predictor of the attitudes and intentions of travelers from individualistic cultures (USA) than those in collectivist cultures (Singapore). This could be why usefulness is more relevant in the Western context of this study. Our findings are also in contrast with earlier studies underpinned by the motivation theory regarding the role of perceived enjoyment in hedonic systems and systems used in leisure environments (e.g., van der Heijden, 2004). There can be several reasons why ease of use seems less influential in this context compared to that of previous research (Ayeh et al., 2013b; Castaneda et al., 2009). First, most Facebook users find that it is easy to use; thus, the variance of the construct is low. Second, we focused on young consumers (Millennials), for whom ease of use is not necessarily related to other constructs in a way that would be expected in older age groups. Third, though ease-of-use is an important antecedent of adoption, earlier scholars assert that it is less critical at the post-adoption stage (Adams et al., 1992) and thus loses its importance with increasing use experience (Ayeh et al., 2016). It should also be noted that the influence of ease of use on intention has been considerably less clear-cut in some recent studies - e.g., Kim (2016) (nonsignificant) and Ayeh et al. (2016) (mixed support).

Our results also found mixed support for traditional TAM-related studies with regard to the relevance of the attitude construct. Attitude seems to mediate the effect of perceived usefulness on intention in the Swedish sample but not in the Italian sample. This reignites the age-old debate in TAM research about the validity of the attitude construct (Castaneda et al., 2009; Davis, 1989; Davis et al., 1989; Davis et al., 1992; Kim et al., 2008; Venkatesh et al., 2003) and yet challenges 
research that ignores this construct in non-work situations (e.g., van der Heijden, 2004). The negligible role of attitude on intention in our study could be attributed to the focus on the utilitarian use of Facebook for travel decision making. Travel is a high-risk product (Lin et al., 2009) and Facebook is primarily used for social networking (not travel planning); hence, users are more likely to exercise their cognitive judgement about the usefulness of the content when using it to make travel decisions than to simply rely on their feelings towards the platform. In other words, travelers may have positive attitude towards Facebook without necessarily intending to use for travel planning. This rationale is corroborated by the strong direct association between perceived usefulness and intention.

The results further reveal that source trustworthiness has a significant direct influence on consumers' attitudes and judgment of content usefulness but not on intention. Prior research also underscores the significance of source credibility in determining users' disposition towards content/information systems (e.g., Ayeh, 2015; Jin et al., 2009; Li, 2013). Accordingly, our study finds that respondents held favorable attitudes toward Facebook content when they believed the source to be trustworthy.

\subsection{Theoretical implications}

While extending the scope of CGM adoption research to non-travel-specific SM in travel decision making contexts, this study corroborates the important role of several antecedents in the decision to use general SM platforms for travel planning. To some extent, this study de-emphasizes the relevance of intrinsic motivational factors such as perceived enjoyment and ease of use for travel planning that have been found relevant in research focusing on travel-specific social media such as TripAdvisor (e.g., Ayeh et al., 2013b). It seems instead to concur with the latest findings that 
Facebook users (especially those involved in Facebook tourism and hospitality brand pages) do not only consider the platform as a means of creating and cultivating social relations but as a source to satisfy functional needs (Ben-Shaul and Reichel, 2018).

In parallel, it confirms that these predictors have weaker effects also in travel-related settings when it comes to non-travel-specific SM usage for travel decisions. Mirroring the polemics of TAM research, the findings seem to support the idea that the attitude construct is appropriate in some (and not all) contexts. Indeed, the results show that only one of the three cognitive factors studied (usefulness) has a direct effect on intention in the overall sample, however attitude is influential on intention in the Swedish subsample and serves as a key mediating variable. This finding could be the consequence of cultural differences between Swedish and Italian respondents. More specifically, Italy and Sweden differ significantly along three dimensions according to the Hofstede framework of cultural differences (Hofstede et al., 2010). Thus, findings call for research to explore the latent implications of uncertainty avoidance, masculinity and indulgence.

\subsection{Practical implications}

Several managerial implications stem from our study. First, the model might help managers in hospitality and tourism understand how travelers assess non-travel-specific SM websites such as Facebook. More specifically, the analysis conducted provides an understanding of the cognitive factors which determine travelers' decision to use non-travel-specific SM for trip planning. Thus, managers should get to know these factors in their effort to influence social media in hospitality and tourism settings and increase the appeal of their hotels ( $\mathrm{Su}$ et al., 2015), shared accommodations (Liu and Mattila, 2017), restaurants, (Kim et al., 2015a) and destinations (Mariani et al., 2016, 2018). Second, SM content should emphasize the utilitarian value for holiday planning 
(extrinsic motivation) rather than the hedonic value and ease of use (intrinsic motivation), as the latter two are already inherent in general SM platforms. This seems to provide a more nuanced appreciation of the findings of recent studies (e.g., Su et al., 2015) emphasizing that Facebook users prefer conversational information which is the typical type of information used in peer-to-peer exchange of opinions and information. Moreover, our study seems to corroborate recent findings suggesting that effective Facebook marketing campaigns should be built with attention to utilityoriented rather hedonic features: short text, one photo at a maximum, and very few colors (Lo and Fang, 2018). Third, the results suggest that the strongest predictor of attitudes and intention in the non-travel-specific SM context is perceived usefulness. This could imply the need for hospitality and tourism managers to invest more time in encouraging friends, acquaintances and previous customers to spontaneously share posts on non-travel-specific social media to enhance the appeal of their services (Su et al., 2015) and ultimately enhance their performance (Zhao et al., 2015). This result seems to resonate with recent research highlighting the need to create fan page communities to enhance the perceived value of tourism and hospitality brands, given the importance that consumers associate with socialization and the impact it has on levels of engagement and behavioral intention (Perez-Vega et al., 2018). Fourth, Facebook is in an ideal position to increasingly build collaborations with some of the major players in online intermediation such as Expedia.com and Booking.com. In the medium term, it is envisioned that online intermediaries in hospitality and tourism will need to find even deeper forms of technological integrations with non-travel-specific SM, beyond bot platforms (Kuchler, 2016), and increasingly deploy social mobile located intelligence within destinations (Buhalis and Foerste, 2015). This could help in making social media even more useful for trip planning as they are already sufficiently enjoyable and easy to use. Fifth, consistent with previous research, our results confirm that hedonic value can play a crucial role in driving perception of usefulness and favorable 
attitude toward using non-travel-specific SM. This might suggest that SM bot platform developers might want to embed hedonic features and humor (Su et al., 2015) to encourage travel consumers' use of social media for planning trips.

Finally, yet importantly, our findings have implications for marketers targeting the specific market segment of young travelers. Recent industry reports suggest that non-travel-specific SM are utilized by young consumers for trip planning as they find the content on Facebook to be useful in getting inspiration for their own travel choices (Foxe, 2016). They also tend to trust the content posted by other travelers on Facebook due to network ties - consistent with tie-strength theory (Gilbert and Karahalios, 2009). Granovetter's (1973) tie-strength theory concerns the role of weak social ties in spreading information. The strength of a tie is measured through frequency of contact, emotional intensity, intimacy, and reciprocal services which characterize the tie (Gilbert and Karahalios, 2009). Accordingly, social media strategists in travel-related sectors and Destination Marketing Organizations (DMOs) should carefully monitor social media use because it can be conducive to travel-related decisions and potentially higher conversion rates among young travelers. Moreover, responding to online reviews from booking engines (e.g., Booking, Expedia) or contributing to TripAdvisor threads is not sufficient anymore. Hospitality and tourism companies should be able to elaborate mechanisms to encourage young non-professional, but influential, travel bloggers to create appealing content on social media that could be interpreted as genuine and thus influence travel planning decisions for other young consumers.

\subsection{Limitations and research agenda}

This study displays a few limitations. First, due to the sampling method, a limitation is the inability to determine whether respondents and non-respondents differ in significant ways. Nonetheless, 
comparing the resulting group of respondents with the general statistics of Internet users in Italy and Sweden suggest that the structure of the sample obtained is quite similar to the typical profile of young Internet users in the countries. The findings of the study can provide valuable comparative insights for social media managers and tourism marketing researchers, considering that penetration rates of Facebook are 50.2 and 62.5 percent in Italy and Sweden respectively (internetworldstats.com, 2017).

The findings suggest key implications for research. The results of this empirical study differ from those obtained by IS adoption studies that apply the TAM in other contexts (Davis, 1989) but also in the context of travel-specific CGM (Ayeh et al., 2013b). In our study, the antecedents identified remain critical, but other variables might influence SM usage in this context as well. Future research could focus on validating these factors and others that might shape usage in this context, such as age and country of origin.

Second, while our study is multi-country as we focused on two European countries (Sweden and Italy), it would be interesting to replicate the study in other countries to investigate the importance of cultural differences in travel consumers' perceptions, attitudes, and intentions. For instance, it could be interesting to conduct a similar study in China with a focus on the Q-Zone platform. Also, the significant difference between the Swedish and the Italian subsamples regarding the mediating role of attitude calls for further research into how Hofstede's cultural dimensions could shape the structural relationships in the model.

Third, our respondents were selected among young people. Although social media is most popular among Millennials (comScore, 2018a), it might be particularly useful to test the model on senior consumers in order to understand if our findings hold regardless of the age of Internet users. Indeed, 
while in absolute terms the share of the overall digital population on Facebook is higher among youngsters, the rate of adoption of Facebook by users aged over 50 has been increasing dramatically over the last 5 years (comScore, 2018b).

Last, further studies might consider how the predictors in the model influence travelers' intention to contribute to content in social networks during and after their travel experiences. This might generate a unified model where the intention to contribute to SM content during and after trip might be linked to the intention to plan a trip by other users. Importantly, reading others' travel-related Facebook content represents a Zero Moment of Truth (ZMOT) (Google, n.d.) for other social media users - hence, intention to use non-travel-specific SM for sharing travel experiences might affect the intention to use it for travel planning. 


\section{References}

Adams, D. A., Nelson, R. R. and Todd, P. A. (1992), "Perceived Usefulness, Ease of Use, and Usage of Information Technology: A Replication", MIS Quarterly, Vol. 16 No. 2, pp. 227-247.

Agag, G. and El-Masry, A. A. (2016), "Understanding consumer intention to participate in online travel community and effects on consumer intention to purchase travel online and WOM: An integration of innovation diffusion theory and TAM with trust", Computers in Human Behavior, Vol. 60, pp. 97-111.

Ajzen, I. (1991), "The theory of planned behavior", Organizational Behavior and Human Decision Processes, Vol. 50, pp. 179-211.

Amaro, S. and Duarte, P. (2013), "Online travel purchasing: A literature review", Journal of Travel \& Tourism Marketing, Vol. 30 No. 8, pp. 755-785.

Amaro, S., Duarte, P. and Henriques, C. (2016), "Travelers' use of social media: A clustering approach", Annals of Tourism Research, Vol. 59, pp. 1-15.

Ayeh, J. K. (2015), "Travellers' acceptance of consumer-generated media: An integrated model of technology acceptance and source credibility theories", Computers in Human Behavior, Vol. 48, pp. 173-180.

Ayeh, J. K., Au, N. and Law, R. (2013a), "“Do We Believe in TripAdvisor?” Examining Credibility Perceptions and Online Travelers’ Attitude toward Using User-Generated Content", Journal of Travel Research, Vol. 52 No. 4, pp. 437-452.

Ayeh, J. K., Au, N. and Law, R. (2013b), "Predicting the intention to use consumer-generated media for travel planning", Tourism Management, Vol. 35, pp. 132-143. 
Ayeh, J. K., Au, N. and Law, R. (2016), "Investigating cross-national heterogeneity in the adoption of online hotel reviews", International Journal of Hospitality Management, Vol. 55, pp. 142-153.

Bagozzi, R. P. (2007), "The legacy of the technology acceptance model and a proposal for a paradigm shift", Journal of the Association for Information Systems, Vol. 8, pp. 244-254.

Bagozzi, R. P. and Yi, Y. (2012), "Specification, evaluation, and interpretation of structural equation models", Journal of the Academy of Marketing Science, Vol. 40 No. 1, pp. 8-34.

Baron, R. M. and Kenny, D. A. (1986), "The Moderator-Mediator Variable Distinction in Social Psychological Research: Conceptual, Strategic, and Statistical Considerations", Journal of Personality and Social Psychology, Vol. 51 No. 6, pp. 1173-1182.

Ben-Shaul, M. and Reichel, A. (2018), "Motives, Modes of Participation, and Loyalty Intentions of Facebook Tourism Brand Page Consumers", Journal of Travel Research, Vol. 57 No. 4, pp. 453-471.

Besbes, A., Legohérel, P., Kucukusta, D. and Law, R. (2016), "A Cross-Cultural Validation of the Tourism Web Acceptance Model (T-WAM) in Different Cultural Contexts", Journal of International Consumer Marketing, Vol. 28 No. 3, pp. 211-226.

Brown, S. A., Venkatesh, V. and Hoehle, H. (2015), "Technology adoption decisions in the household: A seven-model comparison", Journal of the Association for Information Science and Technology, Vol. 66 No. 9, pp. 1933-1949.

Buhalis, D. and Foerste, M. (2015), "SoCoMo marketing for travel and tourism: Empowering cocreation of value", Journal of Destination Marketing \& Management, Vol. 4 No. 3, pp. 151-161. 
Burgess, S., Sellitto, C., Cox, C. and Buultjens, J. (2011), "Trust perceptions of online travel information by different content creators: Some social and legal implications", Information Systems Frontiers, Vol. 13 No. 2, pp. 221-235.

Casaló, L. V., Flavián, C. and Guinalíu, M. (2010), "Determinants of the intention to participate in firm-hosted online travel communities and effects on consumer behavioral intentions", Tourism Management, Vol. 31 No. 6, pp. 898-911.

Castañeda, J. A., Frias, D. M., Munoz-Leiva, F. and Rodríguez, M. A. (2007), "Extrinsic and intrinsic motivation in the use of the internet as a tourist information source", International Journal of Internet Marketing and Advertising, Vol. 4 No. 1, pp. 37-52.

Castaneda, J. A., Frías, D. M. and Rodríguez, M. A. (2009), "Antecedents of internet acceptance and use as an information source by tourists", Online Information Review, Vol. 33 No. 3 , pp. 548-567.

Cheung, C. M., Lee, M. K. and Rabjohn, N. (2008), "The impact of electronic word-of-mouth: The adoption of online opinions in online customer communities", Internet Research, Vol. 18 No. 3, pp. 229-247.

comScore. (2018a), "Facebook \& Snapchat: Age Profiles", available at: https://www.comscore.com/Insights/Presentations-and-Whitepapers/2018/FacebookSnapchat-Age-Profiles (accessed May 9 2018).

comScore. (2018b), "Global digital future in focus 2018", available at: https://www.comscore.com/Insights/Presentations-and-Whitepapers/2018/Global-DigitalFuture-in-Focus-2018 (accessed May 17 2018).

Davis, F. D. (1986), "A technology acceptance model for empirically testing new end-user information systems: theory and results.", Doctoral dissertation, Sloan School of Management, Massachusetts Institute of Technology, Amherst, MA. 
Davis, F. D. (1989), "Perceived usefulness, perceived ease of use, and user acceptance of information technology", MIS quarterly, pp. 319-340.

Davis, F. D., Bagozzi, R. P. and Warshaw, P. R. (1989), "User Acceptance of Computer Technology: A Comparison of Two Theoretical Models", Management Science, Vol. 35 No. 8, pp. 982-1003.

Davis, F. D., Bagozzi, R. P. and Warshaw, P. R. (1992), "Extrinsic and intrinsic motivation to use computers in the workplace", Journal of applied social psychology, Vol. 22 No. 14, pp. 1111-1132.

Dickinger, A. (2011), "The trustworthiness of online channels for experience-and goal-directed search tasks", Journal of Travel Research, Vol. 50 No. 4, pp. 378-391.

Dickinger, A., Lalicic, L. and Mazanec, J. (2017), "Exploring the generalizability of discriminant word items and latent topics in online tourist reviews", International Journal of Contemporary Hospitality Management, Vol. 29 No. 2, pp. 803-816.

Dunbar, R. I. M. (2016), "Do online social media cut through the constraints that limit the size of offline social networks?", Royal Society Open Science, Vol. 3 No. 1.

Facebook. (2018), "Company Info", available at: https://newsroom.fb.com/company-info/ (accessed September 10 2018).

Filieri, R. (2016), "What makes an online consumer review trustworthy?", Annals of Tourism Research, Vol. 58, pp. 46-64.

Findahl, O. and Davidsson, P. (2015), "Svenskarna och internet: 2015 års undersökning av svenska folkets internetvanor [The Swedes and the Internet]", Internetstiftelsen i Sverige (IIS), Stockholm. 
Fornell, C. and Larcker, D. F. (1981), "Evaluating Structural Equation Models with Unobservable Variables and Measurement Error", Journal of Marketing Research, Vol. 18 No. 1, pp. 39-50.

Foxe, K. (2016), "Young travellers more likely to find holiday inspiration on social media", available at: https://www.lonelyplanet.com/news/2016/10/14/travellers-holidayinspiration-social-media/ (accessed November 16 2016).

Gerbing, D. W. and Anderson, J. C. (1988), "An Updated Paradigm for Scale Development Incorporating Unidimensionality and Its Assessment", Journal of Marketing Research, Vol. 25 No. 2, pp. 186-192.

Gilbert, E. and Karahalios, K. (2009), "Predicting tie strength with social media", in Proceedings of the SIGCHI conference on human factors in computing systems. ACM, Boston, MA, USA, pp. 211-220.

Google. (2014), "The 2014 Traveler's Road to Decision", Report, Google, June.

Google. (n.d.), "Zero Moment of Truth (ZMOT)", available at: https://www.thinkwithgoogle.com/collections/zero-moment-truth.html (accessed January 28 2018).

Granovetter, M. S. (1973), "The Strength of Weak Ties", The American Journal of Sociology, Vol. 78 No. 6, pp. 1360-1380.

Hair, J. F., Black, W. C., Babin, B. J. and Anderson, R. E. (2010), Multivariate data analysis: A global perspective, Pearson Education, Upper Saddle River, N.J.

Hair, J. F., Money, A. H., Samouel, P. and Page, M. (2007), Research methods for business, John Wiley \& Sons, Chichester. 
Hays, S., Page, S. J. and Buhalis, D. (2012), "Social media as a destination marketing tool: its use by national tourism organisations", Current Issues in Tourism, Vol. 16 No. 3, pp. 211239.

Hofstede-Insights. (2018), "Country comparison", available at: https://www.hofstedeinsights.com/country-comparison/italy,sweden/ (accessed February 18 2018).

Hofstede, G., Hofstede, G. J. and Minkov, M. (2010), Cultures and Organizations: Software of the Mind, McGraw-Hill USA.

Huh, H. J., Kim, T. T. and Law, R. (2009), "A comparison of competing theoretical models for understanding acceptance behavior of information systems in upscale hotels", International Journal of Hospitality Management, Vol. 28 No. 1, pp. 121-134.

Hung, K. and Law, R. (2011), "An overview of Internet-based surveys in hospitality and tourism journals", Tourism Management, Vol. 32 No. 4, pp. 717-724.

Iacobucci, D. (2010), "Structural equations modeling: Fit Indices, sample size, and advanced topics", Journal of Consumer Psychology, Vol. 20 No. 1, pp. 90-98.

internetworldstats.com. (2017), "Internet in Europe Stats", available at: https://www.internetworldstats.com/stats4.htm (accessed April 13 2018).

Ip, C., Lee, H. A. and Law, R. (2012), "Profiling the users of travel websites for planning and online experience sharing", Journal of Hospitality \& Tourism Research, Vol. 36 No. 3, pp. 418-426.

Jadhav, V., Raman, S., Patwa, N., Moorthy, K. and Pathrose, J. (2018), "Impact of Facebook on leisure travel behavior of Singapore residents", International Journal of Tourism Cities.

Jin, X.-L., Cheung, C. M. K., Lee, M. K. O. and Chen, H.-P. (2009), "How to keep members using the information in a computer-supported social network", Computers in Human Behavior, Vol. 25 No. 5, pp. 1172-1181. 
Kang, M. and Schuett, M. A. (2013), "Determinants of Sharing Travel Experiences in Social Media", Journal of Travel \& Tourism Marketing, Vol. 30 No. 1-2, pp. 93-107.

Kim, J. J. and Fesenmaier, D. R. (2017), "Sharing Tourism Experiences: The Posttrip Experience", Journal of Travel Research, Vol. 56 No. 1, pp. 28-40

Kim, J. S. (2016), "An extended technology acceptance model in behavioral intention toward hotel tablet apps with moderating effects of gender and age", International Journal of Contemporary Hospitality Management, Vol. 28 No. 8, pp. 1535 - 1553.

Kim, M. J., Lee, C.-K., Chung, N. and Kim, W. G. (2014), "Factors Affecting Online Tourism Group Buying and the Moderating Role of Loyalty", Journal of Travel Research, Vol. 53 No. 3, pp. 380-394.

Kim, S., Koh, Y., Cha, J. and Lee, S. (2015a), "Effects of social media on firm value for US restaurant companies", International Journal of Hospitality Management, Vol. 49, pp. 4046.

Kim, T. G., Lee, J. H. and Law, R. (2008), "An empirical examination of the acceptance behaviour of hotel front office systems: An extended technology acceptance model", Tourism management, Vol. 29 No. 3, pp. 500-513.

Kim, W. G., Lim, H. and Brymer, R. A. (2015b), "The effectiveness of managing social media on hotel performance", International Journal of Hospitality Management, Vol. 44, pp. 165171.

Kim, W. G. and Park, S. A. (2017), "Social media review rating versus traditional customer satisfaction: Which one has more incremental predictive power in explaining hotel performance?", International Journal of Contemporary Hospitality Management, Vol. 29 No. 2, pp. $784-802$. 
Kuchler, H. (2016), "Facebook bot platform to transform entire industries", Financial Times, April 13.

Lee, M. K. O., Cheung, C. M. K. and Chen, Z. (2005), "Acceptance of Internet-based learning medium: the role of extrinsic and intrinsic motivation", Information \& Management, Vol. 42 No. 8, pp. 1095-1104.

Lee, W., Xiong, L. and Hu, C. (2012), "The effect of Facebook users' arousal and valence on intention to go to the festival: Applying an extension of the technology acceptance model", International Journal of Hospitality Management, Vol. 31 No. 3, pp. 819-827.

Leung, D., Law, R., Van Hoof, H. and Buhalis, D. (2013), "Social media in tourism and hospitality: A literature review", Journal of Travel \& Tourism Marketing, Vol. 30 No. 12, pp. 3-22.

Li, C.-Y. (2013), "Persuasive messages on information system acceptance: A theoretical extension of elaboration likelihood model and social influence theory", Computers in Human Behavior, Vol. 29 No. 1, pp. 264-275.

Lin, P.-J., Jones, E. and Westwood, S. (2009), "Perceived Risk and Risk-Relievers in Online Travel Purchase Intentions", Journal of Hospitality Marketing \& Management, Vol. 18 No. 8 , pp. $782-810$.

Litvin, S. W., Goldsmith, R. E. and Pan, B. (2008), "Electronic word-of-mouth in hospitality and tourism management", Tourism management, Vol. 29 No. 3, pp. 458-468.

Lo, Y. C. and Fang, C.-Y. (2018), "Facebook marketing campaign benchmarking for a franchised hotel", International Journal of Contemporary Hospitality Management, Vol. 30 No. 3, pp. $1705-1723$. 
Mariani, M. M., Mura, M. and Di Felice, M. (2018), "The determinants of Facebook social engagement for national tourism organizations' Facebook pages: A quantitative approach", Journal of Destination Marketing and Management, Vol. 8, pp. 312-325.

Mariani, M. M., Di Felice, M. and Mura, M. (2016), "Facebook as a destination marketing tool: Evidence from Italian regional Destination Management Organizations", Tourism Management, Vol. 54, pp. 321-343.

Mathieson, K., Peacock, E. and Chin, W. W. (2001), "Extending the technology acceptance model: the influence of perceived user resources", ACM SigMIS Database, Vol. 32 No. 3, pp. 86-112.

Mauri, A. G. and Minazzi, R. (2013), "Web reviews influence on expectations and purchasing intentions of hotel potential customers", International Journal of Hospitality Management, Vol. 34, pp. 99-107.

Moon, J.-W. and Kim, Y.-G. (2001), "Extending the TAM for a World-Wide-Web context", Information \& Management, Vol. 38 No. 4, pp. 217-230.

Morosan, C. (2012), "Theoretical and Empirical Considerations of Guests' Perceptions of Biometric Systems in Hotels: Extending the Technology Acceptance Model", Journal of Hospitality \& Tourism Research, Vol. 36 No. 1, pp. 52-84.

Ohanian, R. (1990), "Construction and validation of a scale to measure celebrity endorsers' perceived expertise, trustworthiness, and attractiveness", Journal of advertising, Vol. 19 No. 3, pp. 39-52.

Pallant, J. (2013), SPSS Survival Manual, McGraw-Hill Education, Berkshire.

Park, H., Xiang, Z., Josiam, B. and Kim, H. (2014), "Personal profile information as cues of credibility in online travel reviews", Anatolia, Vol. 25 No. 1, pp. 13-23. 
Pavlou, P. A. and Fygenson, M. (2006), "Understanding and Predicting Electronic Commerce Adoption: An Extension of the Theory of Planned Behavior", MIS Quarterly, Vol. 30 No. 1, pp. 115-143.

Perez-Vega, R., Taheri, B., Farrington, T. and O'Gorman, K. (2018), "On being attractive, social and visually appealing in social media: The effects of anthropomorphic tourism brands on Facebook fan pages", Tourism Management, Vol. 66, pp. 339-347.

PhocusWright. (2014), "Social Media In Travel: Mayhem, Myths, Mobile \& Money A Phocuswright Special Project", available at: http://www.phocuswright.com/Special-

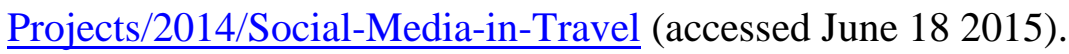

Qu, H. and Lee, H. (2011), "Travelers' social identification and membership behaviors in online travel community", Tourism Management, Vol. 32 No. 6, pp. 1262-1270.

Reichelt, J., Sievert, J. and Jacob, F. (2014), "How credibility affects eWOM reading: The influences of expertise, trustworthiness, and similarity on utilitarian and social functions", Journal of Marketing Communications, Vol. 20 No. 1-2, pp. 65-81.

Ryan, R. M. and Deci, E. L. (2001), "On happiness and human potentials: A review of research on hedonic and eudaimonic well-being", Annual review of psychology, Vol. 52 No. 1, pp. 141-166.

Shim, S., Eastlick, M. A., Lotz, S. L. and Warrington, P. (2001), "An online prepurchase intentions model: The role of intention to search", Journal of Retailing, Vol. 77, pp. 397416.

Sobel, M. E. (1982), "Asymptotic Confidence Intervals for Indirect Effects in Structural Equation Models", Sociological Methodology, Vol. 13, pp. 290-312. 
Statista. (2018), "Distribution of Facebook users worldwide as of July 2018, by age and gender", available at: https://www.statista.com/statistics/376128/facebook-global-user-agedistribution/ (accessed September 10 2018).

Su, N., Reynolds, D. and Sun, B. (2015), "How to make your Facebook posts attractive: A case study of a leading budget hotel brand fan page", International Journal of Contemporary Hospitality Management, Vol. 27 No. 8, pp. 1772-1790.

Teichmann, K. (2011), "Expertise, experience and self- confidence in consumers' travel information search", International Journal of Culture, Tourism and Hospitality Research, Vol. 5 No. 2, pp. 184-194.

tom Dieck, M. C., Jung, T. H., Kim, W. G. and Moon, Y. (2017), "Hotel guests' social media acceptance in luxury hotels", International Journal of Contemporary Hospitality Management, Vol. 29 No. 1, pp. 530-550.

van der Heijden, H. (2004), "User Acceptance of Hedonic Information Systems", MIS Quarterly, Vol. 28 No. 4, pp. 695-704.

Wang, Y., Yu, Q. and Fesenmaier, D. R. (2002), "Defining the virtual tourist community: implications for tourism marketing", Tourism management, Vol. 23 No. 4, pp. 407-417. Wathen, C. N. and Burkell, J. (2002), "Believe it or not: Factors influencing credibility on the Web", Journal of the American society for information science and technology, Vol. 53 No. 2, pp. 134-144.

Venkatesh, V. (2000), "Determinants of perceived ease of use: Integrating control, intrinsic motivation, and emotion into the technology acceptance model", Information systems research, Vol. 11 No. 4, pp. 342-365. 
Venkatesh, V. and Davis, F. D. (2000), "A Theoretical Extension of the Technology Acceptance Model: Four Longitudinal Field Studies", Management Science, Vol. 46 No. 2, pp. 186204.

Venkatesh, V., Morris, M. G., Davis, G. B. and Davis, F. D. (2003), "User Acceptance of Information Technology: Toward a Unified View", MIS Quarterly, Vol. 27 No. 3, pp. 425-478.

Xiang, Z. and Gretzel, U. (2010), "Role of social media in online travel information search", Tourism management, Vol. 31 No. 2, pp. 179-188.

Xiao, H. and Smith, S. L. J. (2007), "The use of Tourism knowledge: Research Propositions", Annals of Tourism Research, Vol. 34 No. 2, pp. 310-331.

Zeng, B. and Gerritsen, R. (2014), "What do we know about social media in tourism? A review", Tourism Management Perspectives, Vol. 10, pp. 27-36.

Zhao, X., Wang, L., Guo, X. and Law, R. (2015), "The influence of online reviews to online hotel booking intentions", International Journal of Contemporary Hospitality Management, Vol. 27 No. 6, pp. 1343-1364. 